\title{
The Application of Salutogenesis to Work
}

\author{
Gregor J. Jenny, Georg F. Bauer, Hege Forbech Vinje, Katharina Vogt, \\ and Steffen Torp
}

\section{Introduction}

In the early twentieth century, Kurt Lewin questioned the role of work and occupational psychology in view of the increasing division of labor (Taylorism), socialism, and a standpoint of a just society. He noted that one's work and occupation is a two-faced matter: a means for living or a purpose in life, something demanding or equally fulfilling. This leaves us with the apparent choice of either working less and more comfortably or making work rich and decent (1920, pp. 11-12). Referring to this early narrative of the working lives of human beings in modern times, Schallberger (2006) summarized that "the role of work in wellbeing and health can be understood only when we describe work simultaneously as a possible source of negative (e.g., work stress) and positive (e.g., pleasure in work) emotional states" (p. 96).

Both the detrimental and the health-promoting consequences of working processes were also subjects of Antonovsky's writing on salutogenesis and sense of coherence at work (1987a): "A distinction must be made between the elimination of stressors and the development of healthenhancing job characteristics" (p. 165). Viewing stressors as entropic-leading to disorder in humans and social

G.J. Jenny $(\varangle) \bullet$ G.F. Bauer $\bullet$ K. Vogt

Division of Public and Organizational Health, Epidemiology,

Biostatistics and Prevention Institute, University of Zürich,

Hirschengraben 84, Zürich 8001, Switzerland

e-mail: gregor.jenny@uzh.chhttp://www.ebpi.uzh.ch; georg.

bauer@uzh.chhttp://www.ebpi.uzh.ch; kvogt@bluemail.ch

H.F. Vinje $\bullet$ S. Torp

Department of Health Promotion, University College of Southeast

Norway, P.O. Box 235Kongsberg 3603, Norway

e-mail: hege.f.vinje@hbv.nohttp://www.hbv.no; steffen.torp@hbv.

nohttp://www.hbv.no systems-sense of coherence "represents the forces of negative entropy $[\ldots]$ preventing initial tension from being transformed into stress" (pp. 156-157). Given his view that sense of coherence is to a large extent static after an individual reaches adulthood, priority should be on young people's working conditions, which is also a reminder of how destructive unemployment is for this cohort. However, also for older workers, sense of coherence "can be modified, detrimentally or beneficially, by the nature of the working environment" (p. 165). Many studies have shown this volatility of sense of coherence and the influences of the work environment on its manifestation (Feldt, Kinnunen, \& Mauno, 2000; Togari, Yamazaki, Nakayama, \& Shimizu, 2007). Antonovsky elaborated on work characteristics that potentially are related to sense of coherence, offering a dense description of a workplace where individuals experience meaningfulness, manageability, and comprehensibility. This idea has subsequently been picked up by many others (cf. Bringsén, Andersson, Ejlertsson, \& Troein, 2012; Hanson, 2007; Idan, Braun-Lewensohn, \& Sagy, 2013; Nilsson, Andersson, Ejlertsson, \& Troein, 2012; Udris, 2006; Vaandrager \& Koelen, 2013).

This chapter presents models, measures, and intervention approaches that relate to the double nature of work and its salutogenic quality. Hereby, the view of Antonovsky is enhanced insofar that health-promoting, salutogenic job characteristics are not solely understood as mitigating the pathogenic effects of stressors at work, but have a distinct effect on positive health outcomes. In the following sections, Antonovsky's original model is first specified and simplified for the context of work. Next, Antonovsky's line of thinking is related to frameworks researching job resources and demands. After a review of the prevalence of salutogenic measures in worksite health promotion, the point of making salutogenesis more visible in work-related research and practice is elaborated. This is illustrated with a practical example of a survey-feedback process promoting salutogenic work. 


\section{General Resistance Resources and Sense of Coherence in the Context of Work}

"[...] the strength of the sense of coherence [...] can be modified, detrimentally or beneficially, by the nature of the current working environment" (1987a, p. 165). Given the fact that most people spend a big part of their waking hours at work, working conditions are important determinants of their sense of coherence and therefore also of a person's, a family's, and even a community's health. In order to be salutogenic, work needs to be comprehensible, manageable, and meaningful: Antonovsky (1987a, p. 157ff.) emphasized consistency, underload-overload balance, and opportunities to participate in decision-making as important life-and work-experiences, supporting the perception of comprehensibility, manageability, and meaningfulness, thus building up the sense of coherence of employees.

Based on Antonovsky's writing on health-promoting factors at work (1987a), his original model of salutogenesis is specified and simplified for the context of work (Fig. 20.1): Job resources are part of the generalized resistance resources that allow for coherent work experiences, which help build up the sense of coherence of employees. Sense of coherence then influences the ways in which an individual perceives, appraises, and copes with stressors in working life, or the so-called job demands, and the tension they induce. An employee with a high sense of coherence might, for instance, perceive and appraise the demands of his/her work environment as challenging rather than threatening. Furthermore, that employee will feel confident that resources are available to cope with the demands and he/she will also be more likely to select an appropriate coping strategy. Successful coping will determine an individual's position on the health continuum. Experiences of successful coping can also help build up future sense of coherence. Finally, good health is a requirement for building and maintaining generalized resistance resources and job resources, respectively, just as stressors can diminish generalized resistance resources. Such reciprocal mechanisms-depicted as dotted lines in Fig. 20.1-have also found empirical support in research on gain and loss spirals (cf. Hakanen, Perhoniemi, \& Toppinen-Tanner, 2008; Salanova, Llorens, \& Schaufeli, 2011).

\section{Cultural Context}

Working processes emerge within organizations as social systems (Bauer \& Jenny, 2012; Jenny \& Bauer, 2013), which themselves emerge within and interact with societal, political, ecological, and cultural environments and systems. As elaborated later, Antonovsky demanded "social-historical awareness" (1987a, p. 159) when researching occupational stress and the role of meaning at work. On the one hand, it seems clear that meaning at work will have very different antecedents and connotations between occupational, hierarchical, and regional groups. For example, Western European economies have heavily shifted from production to service-provider industries. Intuitively, one would not tend to study Asian sweatshop laborers and European bank managers with the same concept and identical measures of meaning at work.

On the other hand, local and global structures and cultures are interwoven more strongly than ever, connected through trade, international corporations, transport, travel, and communication. Furthermore, universal human needs, such as autonomy, competence, and belongingness, have been postulated (Deci \& Ryan, 1985), which makes a point for defining global criteria for salutogenic work and shared conceptions of meaning at work.

Similarly, sense of coherence has been studied across various cultural backgrounds, also in regard to work. This also matches the generic, psychosocial focus of generalized resistance resources, sense of coherence, and of the perception, appraisal, and coping with stressors. There are global approaches to work and health at the institutional level; the World Health Organization (WHO) has produced a "Declaration on Workers Health" (WHO, 2006), a "Global Plan of Action" for workers' health (WHO, 2007, 2013), and a "Global Framework for Healthy Workplaces" (WHO, 2010). Similarly, the International Labor Organization (ILO) lists youth employment and social security protection
Fig. 20.1 Simplified specification of Antonovsky's original model of salutogenesis for the context of work (1987a)

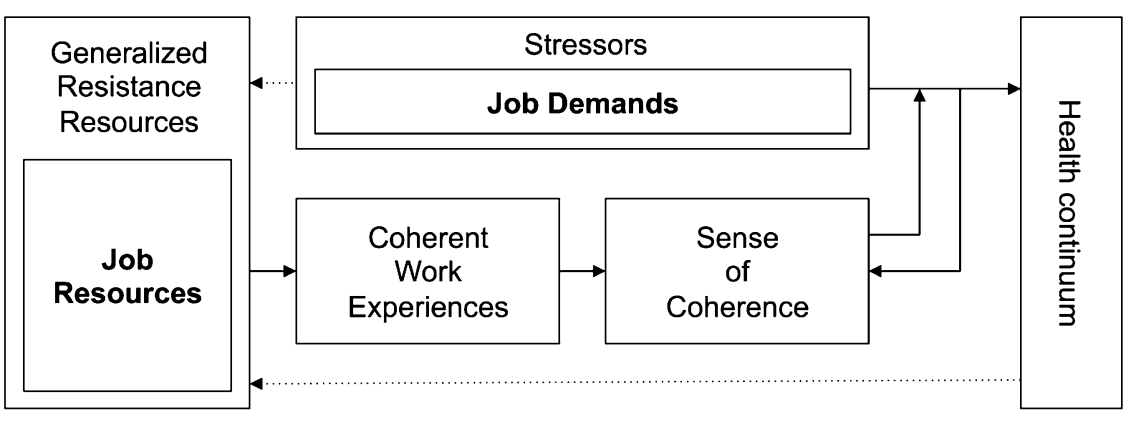


as two global key issues and calls for job creation in general, "[...] as work is the way out of poverty for poor households and...the expansion of productive and decent employment [emphasis ours] is the way economies grow and diversify" (ILO, 2014).

\section{Practice Context}

There is considerable differentiation among experts with regard to work, safety, and health. Without going into detail, practice taps into the fields of occupational health and safety, occupational medicine, workplace health promotion, human resources management, ergonomics, organizational change and development, coaching, social services, etc. Bridging the logics and approaches of these disciplines is needed to assure that companies and their employees can benefit from this profound knowledge base (Bauer \& Hämmig, 2014). Some of these practices stress the importance of building and strengthening resources for employee health, wellbeing, and productivity, implicitly or explicitly indicating a salutogenic perspective. In regard to workplace health promotion (WHP), for example, the European Network for Workplace Health Promotion (ENWHP) incorporates salutogenic thinking in its Luxembourg Declaration from 1997 (ENWHP, 2005): it postulates comprehensiveness as an important principle of WHP and demands that WHP "[...] combines the strategy of risk reduction with the strategy of the development of protection factors and health potentials [emphasis ours]." Such resource-oriented capacity-building extends from the individual's personal resources and health to the system(s) he/she interacts with (cf. Hoffmann, Jenny, \& Bauer, 2014).

\section{Research on the Role of Sense of Coherence at Work}

The aforementioned multitude of experts in the field of work and health are mirrored by a multitude of research disciplines (Bauer \& Hämmig, 2014). As the introductory quote by Lewin indicated, psychology has a long tradition in researching work, health, and well-being outcomes, from which among others the subdiscipline of "occupational health psychology" has emerged (Adkins, 1999). Similarly, sociology - the discipline Antonovsky was engaged in-has its stakes in this field of research. Sciences such as occupational medicine and ergonomics have gathered in-depth evidence on the physical side of human beings and their material environments.

Again, some of these disciplines incorporate a-mostly implicit-salutogenic perspective and conduct research on resources and positive health and well-being outcomes (cf. Bakker \& Derks, 2010, on "Positive Occupational Health Psychology"). Hereby, levels of analysis reach from the micro (occupational health) and meso (organizational health) to the macro (public health) levels (Bauer \& Hämmig, 2014).

Many studies have empirically explored the effect of sense of coherence in the context of work, testing its direct, moderating, and mediating effects. For example, Albertsen, Nielsen, and Borg (2001) found direct effects of sense of coherence on stress symptoms in a large sample of more than 2000 Danish employees with diverse professional backgrounds. This is in line with previous results by Feldt (1997), who found that sense of coherence was related directly to less psychosomatic symptoms and emotional exhaustion in a sample of nearly 1000 technical designers. She also reported a moderating effect, i.e., that people with a high sense of coherence were better protected from the negative effects of unfavorable working conditions.

A mediating effect was found in a longitudinal study by Feldt et al. (2000), who showed that a good organizational climate and job security strongly correlated with a high sense of coherence, which in turn was associated strongly with well-being. Albertsen et al. (2001) also reported a mediating effect of sense of coherence on the relationship between an unfavorable working environment and symptoms of stress. For a recent list of studies researching sense of coherence with regard to work, we refer to Mayer and Krause (2011) and the chapter by Eriksson in this book. Based on this solid base of evidence, it can be concluded that sense of coherence (a) is influenced by various aspects of work and organization, (b) influences work-related outcomes, such as burnout and stress symptoms, and (c) moderates the effects of unfavorable working conditions on health outcomes.

\section{Job Demands, Control, and Support-A Salutogenic Pathway}

The Luxembourg Declaration on Workplace Health Promotion in the European Union (ENWHP, 2005), one of the most important documents giving guidelines on research and practice in workplace health promotion, underlines the need to create work that balances workers' job demands, job control (decision latitude), and support from colleagues and supervisors. This is the main focus of the well-known job demand-control-support (DCS) model by Karasek and Theorell (1990). The model has two main hypotheses. The strain hypothesis predicts that jobs with high mental job demands and low control or social support lead to mental strain and thereby mental and physical illness among workers. The second, and much less-investigated, hypothesis is the active learning hypothesis. This hypothesis could 
be regarded as a salutogenic pathway and predicts that high mental job demands in combination with a high degree of control and support will lead to increased learning, motivation, and a feeling of mastery.

This increased learning and feeling of mastery will, according to Karasek and Theorell (1990), inhibit perceptions of work-related strain and associated health problems and will thus mediate the effect of work factors on strain and health. When Karasek and Theorell (1990, p. 101) described the inhibiting effect of learning and mastery on strain and diseases, they actually referred to Antonovsky's (1987b) sense of coherence concept as a related concept that fits with the mastery orientation of the DCS model. Most studies more or less confirm the strain hypothesis of the DCS model (Van der Doef \& Maes, 1999), but the proposed mediating effects that learning and mastery may have on the relationships between demands, control and support, and health and disease have almost not been investigated.

A study among a general working population in Norway, Torp, Grimsmo, Hagen, Duran, and Gudbergsson (2013) first investigated whether psychological job demands, personal control, and social support affect the negative health measure of depression differently than the positive measure of work engagement. The study showed that high control and social support were associated with a low score on depression and a high score on engagement. Demands correlated positively with depression but showed no significant association with engagement.

Secondly, the study hypothesized that the positive measure of engagement could have the same effect as the learning and mastery variables in the DCS model and that this variable could mediate the effect of psychosocial work factors on depression. In accordance with other studies (Hallberg \& Schaufeli, 2006; Peterson et al., 2008), the results showed that workers reporting high engagement reported fewer symptoms of depression, and the mediation analyses indicated that engagement partially mediated the effects of work control and support on the level of depression. Other studies have shown similar mediation effects on other outcomes, such as organizational commitment (Hakanen, Bakker, \& Schaufeli, 2006) and organizational citizen behavior (Saks, 2006).

\section{The Job Demands-Resources (JD-R) Model Viewed Through the Lens of Salutogenesis}

The above study applied the DCS model to postulate a salutogenic pathway, where work engagement mediates the direct impact of job control and support on symptoms of depression. The study also showed the direct relationship of job control and support with work engagement as a positive outcome. In this section, the Job Demands-Resources (JD-R) model is used to elaborate this expanded salutogenic effect of job resources on positive health outcomes. The JD-R model-originally a model developed to explain burnoutbroadens the DCS model by looking at job resources beyond control and support and particularly by emphasizing the positive pathway between job resources and work engagement.

The JD-R model classifies job characteristics into two categories. Job resources are positively valued physical, social, or organizational aspects of the job that are functional in achieving work goals, reducing job demands, or stimulating personal growth and development (Schaufeli \& Taris, 2014). Job demands are negatively valued physical, social, or organizational aspects of the job that require sustained physical or psychological effort and are therefore associated with certain physiological and psychological costs. Similar to the DCS model, the JD-R model describes two distinct processes (Bakker \& Demerouti, 2007): a positive, motivational process and a negative, health-impairing process.

The health-impairment process explains the exhausting impact of chronic job demands (e.g., work overload or time pressures) on burnout, whereas the motivational process shows how job resources (e.g., social support or autonomy) have a motivating potential and lead to high work engagement. There is much empirical support for these two processes and their impact on burnout and engagement, as well as on organizational outcomes (Van den Broeck, Van Ruysseveldt, Vanbelle, \& de Witte, 2013). In addition, the model postulates crosslinks and interactions, where job resources may buffer the health-impairment process (cf. Bakker, Demerouti, \& Euwema, 2005) and job demands may influence the motivational process (cf. Bakker, Hakanen, Demerouti, \& Xanthopoulou, 2007).

\section{Adding Salutogenesis: The JD-R Health Model}

The JD-R model has empirically shown that resources stimulate personal growth and development. Humans draw on resources not only to be resilient with regard to potentially harmful situations and events, but to strengthen their standing in life and work, and to achieve their goals. Research has also shown that work engagement is related to various general well-being outcomes (Hakanen \& Schaufeli, 2012; see above too).

Viewing the JD-R model through the lens of salutogenesis, the health-impairment process could be labeled as a "pathogenic path" leading to ill health and the motivational process as a "salutogenic path" leading to positive health (see Fig. 20.2). This dual pathway or analytical perspective has been postulated by the EUHPID model 
Fig. 20.2 JD-R Health-SoC Model (Bauer \& Jenny; based on Brauchli, Jenny, Füllemann, \& Bauer, 2015) (bold = original salutogenic path)

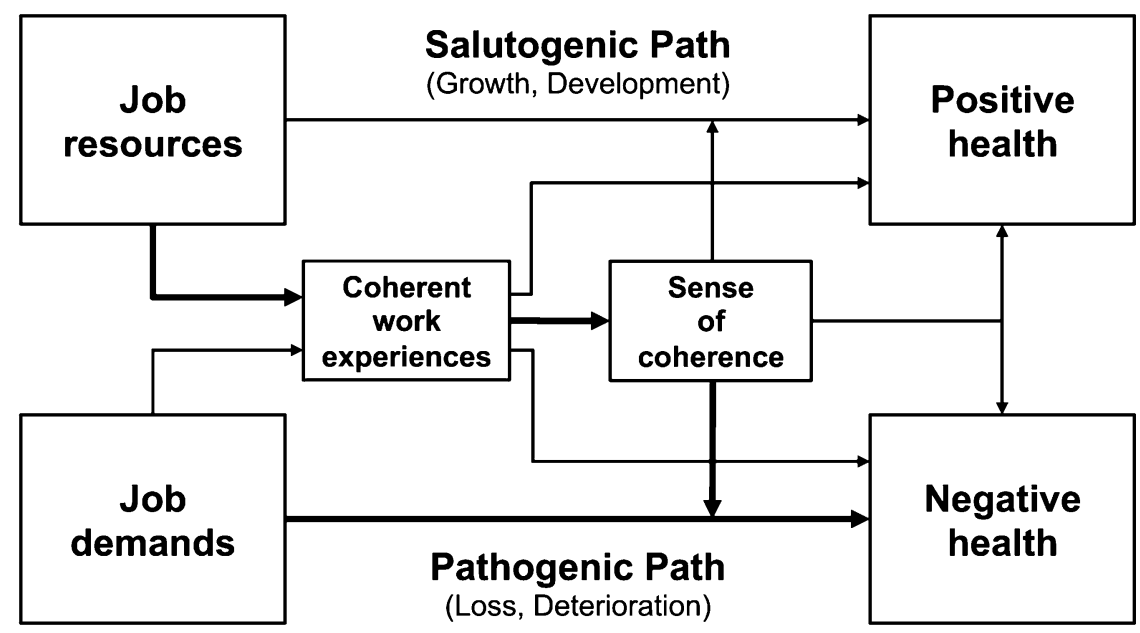

(Bauer, Davies, \& Pelikan, 2006), splitting the ease-disease health continuum conceptualized by Antonovsky into two orthogonal factors of positive and negative health. As research on mental health and illness has shown (cf. Keyes, 2007), positive and negative health statuses share common variance, yet can be perceived as two interrelated but independent factors. From this combination of models, first the broader organizational health development (OHD) model (Bauer \& Jenny, 2012) and later the JD-R Health Model emerged (Brauchli et al., 2015).

The pathogenic path of the JD-R Health Model describes a process in which job demands lead to loss and deterioration, resulting in negative health. Negative health is defined in this model as impaired physical, mental, and social selfreproduction, an outcome traditionally linked to medical classification systems. Examples are musculoskeletal disorders, anxiety states, depressive moods, and social alienation and exclusion. The salutogenic path describes a process in which job resources lead to growth and development and thus to positive health. Positive health is defined as physical, mental, and social self-fulfilment. Examples are energetic fitness, joy and happiness, and being embedded in harmonious relationships.

\section{The Dynamics of Job Resources}

The postulated salutogenic path leading from job resources to positive health requires an understanding of the dynamics of job resources. As discussed above, besides dealing with job demands, job resources are functional in achieving work goals and stimulating personal growth, learning, and development, thus triggering an extrinsic and/or intrinsic motivational process (cf. Schaufeli \& Taris, 2014, for a summary and corresponding theories). Further, research has examined gain cycles, showing that job resources not only lead to work engagement over time, but that work engagement also enhances future job resources (Hakanen et al., 2008; Salanova et al., 2011).

The stability and change of job resources and demands has also been studied, showing that compared to job demands, job resources are more stable (Brauchli, Schaufeli, Jenny, Füllemann, \& Bauer, 2013). This could be due to the fact that job demands are often strongly dependent from factors in an organization's environment (such as economic turmoil, market demands, the labor market), whereas job resources are mainly built and stabilized within an organization. Therefore, interventions building job resources may have more sustainable effects than interventions reducing job demands.

\section{The Role of Sense of Coherence in the Salutogenic and Pathogenic Pathways}

As suggested by Antonovsky and visualized in Fig. 20.1 for the work context, job resources can, through coherent work experiences and sense of coherence, buffer the effects of job demands on negative health. This path is marked in bold in Fig. 20.2. Research shows that job resources and job demands influence the perception of a coherent work situation (Bauer, Vogt, Inauen, \& Jenny, 2015; Vogt, Jenny, \& Bauer, 2013; see below), which again may influence the general sense of coherence of employees and therefore their health status.

Research also shows that coherent work experiences partially mediate the relationship between job resources and engagement as indicators of positive health, as well as between job demands and exhaustion as indicators of negative health (Vogt et al., 2013). These results suggest that coherent work experiences seem to play a role in both of the otherwise distinct positive and negative pathways. The mechanisms of influence need to be further explored and tested for differential effects: it could be hypothesized that 
Fig. 20.3 English version of the Work-SoC scale (Vogt et al., 2013)

\begin{tabular}{|c|c|c|c|c|c|c|c|c|c|}
\hline \multicolumn{10}{|c|}{ How do you personally find your current job and work situation in general? } \\
\hline $1 \mathrm{r}$ & manageable & ○ & $\circ$ & ○ & ○ & ○ & ○ & ○ & unmanageable \\
\hline 2 & meaningless & ○ & $\circ$ & ○ & ○ & ○ & ० & ○ & meaningful \\
\hline $3 r$ & structured & ० & $\circ$ & $\circ$ & ○ & ○ & 0 & ○ & unstructured \\
\hline $4 r$ & $\begin{array}{l}\text { easy to } \\
\text { influence }\end{array}$ & o & ○ & ○ & o & o & 0 & $\circ$ & $\begin{array}{l}\text { impossible to } \\
\text { influence }\end{array}$ \\
\hline 5 & insignificant & 0 & $\circ$ & $\circ$ & o & 0 & o & $\circ$ & significant \\
\hline $6 r$ & clear & ० & ○ & ○ & o & o & ० & ○ & unclear \\
\hline $7 r$ & controllable & 0 & $\circ$ & $\circ$ & 0 & 0 & 0 & $\circ$ & uncontrollable \\
\hline 8 & unrewarding & ० & ० & $\circ$ & o & o & o & $\circ$ & rewarding \\
\hline $9 r$ & predictable & 0 & $\circ$ & 0 & 0 & o & 0 & 0 & unpredictable \\
\hline
\end{tabular}

experiencing meaning at work is more relevant for the salutogenic path, whereas experiencing comprehensibility and manageability is more relevant for the pathogenic path.

Finally, as mentioned above, general sense of coherence buffers the effects of job demands on negative health outcomes by influencing the perception of, appraisal of, and coping with job demands. Similarly, sense of coherence could influence the salutogenic path: a first longitudinal study in this regard did not find any moderating effects of sense of coherence on the relationship between job resources and work engagement, but showed that job resources predicted sense of coherence, and that sense of coherence predicted work engagement (Vogt et al., accepted). Furthermore, sense of coherence also predicted job resources, suggesting a reciprocal relationship between job resources and sense of coherence.

\section{Work-SoC: Measuring Coherent Work Experiences}

As shown in Figs. 20.1 and 20.2, a coherent work experience is a relevant factor influencing both the general sense of coherence of employees and also their appraisal and handling of job resources and job demands. One way of measuring coherent work experiences was proposed by Bauer and Jenny (2007) with the concept of Work-Related Sense of Coherence (Work-SoC). Work-SoC is defined as the perceived comprehensibility, manageability, and meaningfulness of an individual's current work situation (Bauer et al., 2015; Vogt et al., 2013). The conceptualization of Work-SoC assumes that this perception of comprehensibility, manageability, and meaningfulness is influenced by the interaction between individual characteristics and the characteristics of the working environment (Vogt et al., 2013).
"Comprehensibility" describes the extent to which a work situation is perceived as structured, consistent, and clear, "manageability" describes the extent to which an employee perceives that adequate resources are available to cope with the demands in the workplace, and "meaningfulness" describes the extent to which a situation at work is seen as worthy of commitment and involvement. Based on the German edition of Antonovsky's book "Unravelling the Mysteries of Health" (1987b), adjectives were extracted from his description of sense of coherence and matching counterparts were added. This procedure led to a nine-item questionnaire, which has been translated into Norwegian, Swedish, Finnish, French, Italian, and English (see Fig. 20.3), and is also being applied in several ongoing intervention studies.

A first validation study (Bauer et al., 2015), with over 1000 employees from heterogeneous companies, showed that the nine-item questionnaire has a good internal consistency (Cronbach alpha $=0.83$ ) and identified a three-factor structure of the scale with the subdimensions of comprehensibility, manageability, and meaningfulness, with alphas ranging from .72 to .84 . A second study using a large dataset of over 3000 employees could show that Work$\mathrm{SoC}$ is influenced by the job resources and job demands of the current work situation (Vogt et al., 2013). The study also showed that Work-SoC acts as a partial mediator of the relationship between job resources and work engagement and between job demands and exhaustion. The nineitem questionnaire of Work-SoC has a good internal consistency (Cronbach alpha $=0.83)$ (Vogt et al., 2013). Furthermore, multiple group analyses showed that the scale structure is invariant across genders, different age groups, level of education, job position, and time at the job, providing evidence for its robustness. Accordingly, observed changes in Work-SoC, e.g., after interventions, can be attributed to actual changes in the values of Work- 
SoC and not to changes in the structure or measurement of the construct. From this it is concluded that the Work-SoC scale can be used as a practical instrument for assessing the salutogenic quality of work and can make it visible in a simple and reliable way.

\section{Self-Tuning: Promoting and Protecting a Meaningful Work-Life}

Antonovsky did not dwell on health promotion in different work settings, but left it to future researchers and practitioners to translate his ideas into specific work-life contexts. The concept of self-tuning has evolved from an in-depth, qualitative exploration of the nature of job engagement among thriving Norwegian community health nurses, and investigates how job engagement may be maintained and promoted (Vinje, 2007; Vinje \& Mittelmark, 2006). The concept has been further explored among Ugandan nurses (Bakibinga, Vinje, \& Mittelmark, 2012) and in the work-life of nurses and other health care workers in municipal health services in Norway (Vinje \& Ausland, 2013). Although Antonovsky (1987a) stressed the need for the right loadbalance to manage well at work, meaningfulness seems to be the key issue in his argument. This is the case in the above-mentioned research: the concept of "meaning" in and of life seems essential in health care workers' experience of job engagement, and it helps develop the job engagement construct, in which the search for meaning, the experience of meaning, and holding onto meaning has the force of a drive (Vinje, 2007). The self-tuning model of self-care (Fig. 20.4) therefore depicts job engagement as part of a bigger picture involving two different processes: a salutogenic one and a pathogenic one.

Although "calling" is a highly secular phenomenon for the Norwegian participants in these studies (Vinje, 2007) and a decidedly religious one for the Ugandan participants (Bakibinga et al., 2012), this research reveals that nurses have high levels of ethical standards and a sense of calling as a core aspect in their lives. The ability to listen to and act upon a calling helps an individual prioritize and choose when it comes to work. Thus, the motivational factor in job engagement is a sense of calling and the calling/vocation match. Research indicates that to promote job engagement, acknowledgment of the importance of values and possible value conflicts between the person, the profession, and the workplace is vital, both before a choice of profession is made and on a continuing basis during one's working life (Vinje \& Mittelmark, 2008). The calling/vocation match brought forth from introspection, sensibility, and reflection stimulates job engagement and produces a working situation that for the most part feels deeply gratifying and meaningful to the individual, resulting in zest for work and vitality. A wish to protect these experiences of work-related well-being enhances this salutogenic process.

Research demonstrates that job engagement may contribute to exhaustion and burnout, not only health and wellbeing (Vinje \& Mittelmark, 2007). The thriving nurses had experienced stress bringing them close to burnout, yet they had all regained enthusiastic engagement in nursing by the time of participation in the study. The results revealed a pathogenic process in which job engagement played a double-edged role that brought nurses to the brink of burnout. High job engagement (which followed from the nurses'
Fig. 20.4 The self-tuning model of self-care (First published in: Vinje, H.F. \& Mittelmark, M.B. (2006). Deflecting the path to burnout among community health nurses: How the effective practice of self-care renews job engagement. The International Journal for Mental Health Promotion. Vol 8 (4), pp 36-47; The model is slightly revised by the authors since this publication.)

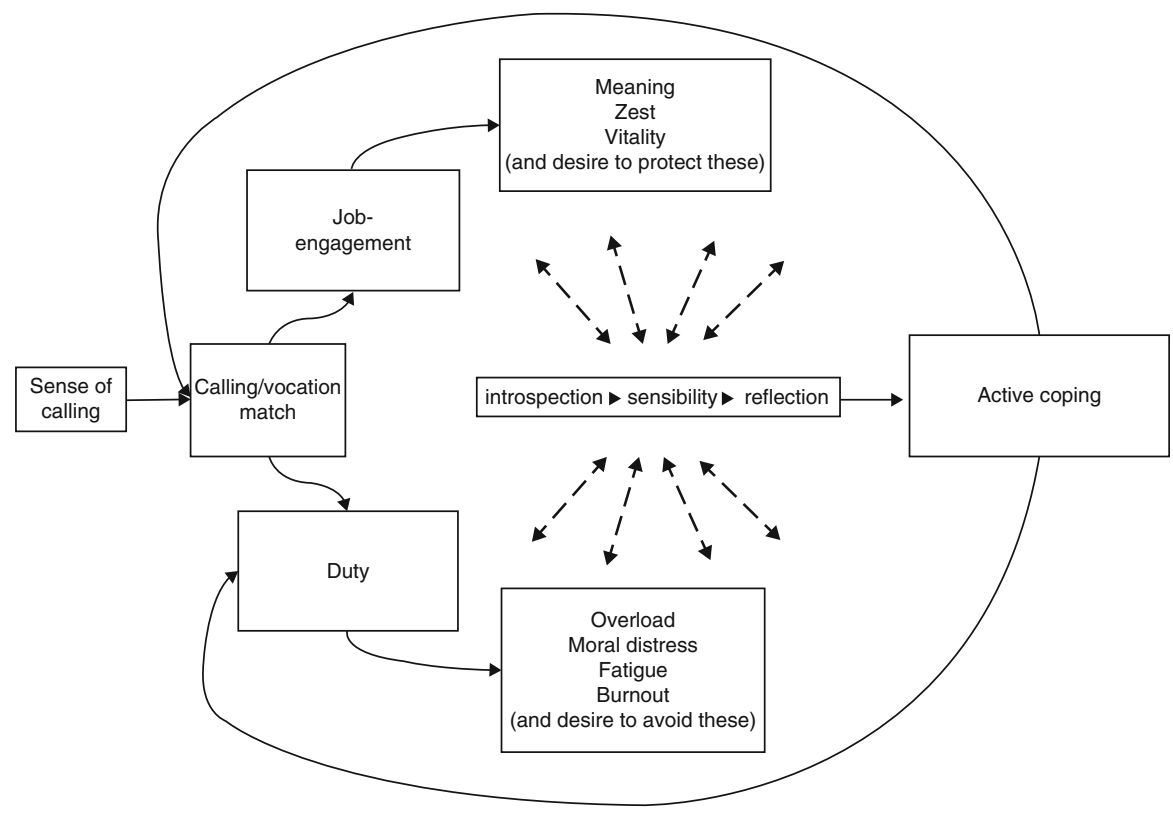


sense of calling and the calling/vocation match) contributed to a strong sense of duty and heavy self-demand regarding their own and others' levels of performance. The need to experience and hold onto meaning tended to overshadow the importance of manageability of one's professional responsibilities. The study indicated that moral distress, overload, and fatigue leading to near-burnout may be intensified by a high level of job engagement and frustration about not living up to one's high ethical standards. Thus, job engagement appears to play a paradoxical role in nurse burnout, expressed through a pathogenic process leading to poor functioning, but also to a desire to avoid these detrimental experiences (Vinje \& Mittelmark, 2007). This brings us to the mediating process in the self-tuning model: the actual self-tuning practice.

Self-tuning is a sensing/reacting process with the purpose of finding, protecting, and regaining meaning, zest, and vitality in a person's work-life. Studies from Norway and Uganda show that the actual active coping strategies, such as "striving to be a realistic idealist," "engaging in meaningful activities alongside nursing," "ensuring a place for silence and withdrawn peace," and "solving emotional problems," might differ between the cultures. But the studies demonstrated also that introspection, sensibility, and reflection are independent of setting. Self-tuning is adaptive in that it can result in changes leading to regaining job engagement. The nurses' abiding existential curiosity about the surrounding world and about the self resulted in stimulation of self-monitoring and self-tuning in their search for coherence-a sense of coherence that resonates from their personal values and into the lived expression of them through valued work (Vinje, 2007). Relative constant introspection takes place in the form of sensibility. Sensibility is a pre-reflective, preverbal ability. It is moments of passive receptiveness of signals from self and others; these are captured, accepted, and made the object of reflection regardless of whether they point towards improvement or deterioration (Nortvedt \& Grimen, 2004; Vinje \& Mittelmark, 2006). To avoid burnout and to enhance job engagement, the nurses worked to lower the too-rigorous standards they had set for themselves and for others (arrow from active coping to duty), and/or they changed jobs or modified their working conditions (arrow from active coping to calling/ vocation match).

Eagerness to preserve a meaningful working life aligns with Antonovsky's (1987a) advice concerning the probable negative effects on health from frustrated personal potential. He claims that one's skills, abilities, interests, and potential must have a channel for expression in the given cultural and social setting one lives in, hence bringing attention to society's influence on the experience of having a valued job. If job engagement and work-related well-being is a goal, one cannot, according to Antonovsky, deal "[...] objectively with immediate job conditions and subjectively with the ways in which those conditions are perceived, with complete disregard for the historical and broader social structure within which the job is embedded" (1987a, p. 159). This underlines the importance of understanding and finding one's place and role in the social and cultural structure with respect to creating meaningful life experiences.

In many ways, it seems safe to claim that the self-tuning process is designed to promote, protect, and enhance a meaningful work-life. In everything participants in the aforementioned studies say about what drives them towards their line of work, it is finding meaning in the sense of being useful and in helping patients and clients find contentment and have a good quality of life, that is most prominent. They are all genuinely concerned and highly committed to their field. High service-quality is of utmost importance and they strive to ensure that the service to patients and clients will be useful (Vinje \& Ausland, 2013, p. 895): "[. . .] zest for work is being able to give [...] being allowed to exist for others." Antonovsky (1987a) argued that one can draw strength from a truly culturally valued enterprise.

In exploiting the enterprise's meaning, one can find energy to endure difficult working conditions, at least for a period of time. However, he emphasizes that if the organization one invests one's energy in is not historically and socially well regarded, it is likely that the immediate working conditions will overshadow the larger picture. The research presented here broadens this view, as the results demonstrate the importance of a match between personally held, professionally embedded, and organizational claimed values in order to experience meaningfulness and a sense of usefulness (Vinje \& Ausland, 2013; Vinje \& Mittelmark, 2008). If the practice of self-tuning helps in ensuring a match between these three sets of values, one seems to be more robust in the face of societal depreciation.

Teaching practice has informed recent research and illustrates that combining self-tuning individually and in groups in workplaces generates a sense of a broadened scope of action, and thus facilitates active coping for the workers (Vinje \& Ausland, 2013). The self-tuning process results in the health care workers expressing work-related well-being characterized both by the feeling and the evaluation of being in a good work situation, as well as the wish to offer their resources to the workplace. The practice of selftuning may be referred to as "salutogenic capacity building," i.e., a competency at the individual and/or group level with the potential to reinforce sense of coherence and promote well-being at work (Vinje \& Ausland, 2013). Thus, the assumption is made that self-tuning exemplifies mechanisms needed to ensure coherent work experiences and to translate them into sense of coherence (see Fig. 20.1). Intervention studies are needed to generate evidence of this causal mechanism. 


\section{Pathogenic and Salutogenic Health Measures in the Context of Workplace Health Promotion}

Since workers' health is closely related to enterprise and national productivity, work is also important for the living conditions of societies and thereby also for the health of the general population. How work-related health is defined and measured in health and safety practice and research will inevitably affect the focus of health and safety policy at both enterprise and national levels. Mittelmark and Bull (2013) hold that health-promotion practice and research should accept a wide range of both pathogenic and salutogenic health measures. Nevertheless, the salutogenesis research summarized by Eriksson and Lindström (2005) shows that most studies have defined health in a traditional pathogenic way and, to a far lesser extent, have made use of positive health concepts.

In the realm of occupational health, Torp and Vinje (2014) investigated how workplace health-promotion studies defined and measured health. In their scoping review, they included 63 health-promotion intervention research studies performed and published by Nordic researchers from 1986 until 2014. Based on a qualitative content analysis of the studies' descriptions of the used health outcomes, six categories of health-related measures were identified; health behavior, disease and injury, absenteeism, work ability, general health, and positive health. The health behavior category included mainly lifestyle measures, such as healthy eating, physical activity, and non-smoking, that is, healthrelated behaviors that were mostly detached from the core activities of the enterprise (the production of goods and services). The disease and injury category included traditional health measures defined as the absence of disease or injury.

Examples are mental disorders, musculoskeletal pain, allergies, psychological strain, and accidents. The absenteeism category included general absenteeism, sick leave (prescribed and not prescribed by a physician), and disability retirement. Work ability may seem to be a positive health measure, but most studies defined work ability in terms of reduced ability to work because of symptoms related to disease in addition to more positive factors. The general health category included, for instance, single-item questions such as "In general, how would you describe your health?" and multi-item measures of health-related quality of life such as the well-known SF-36 instrument (Stewart, Hays, \& Ware, 1992). Like the work ability measures, the healthrelated quality of life indices used questions related both to health problems and to positive indicators of health. The measures included in the positive health category were related to well-being or other explicitly positive health conditions such as multi-item measures of self-esteem, coping, work engagement, and job satisfaction. Except for the measures included in the work ability category, most measures in the other categories were general and not workrelated measures of health.

Overall, one can say that approximately three quarters of the measures used in the workplace health-promotion studies were categorized as pathogenic measures (health behavior, disease and injury, and absenteeism), one eighth as salutogenic measures (positive health), and another eighth including both salutogenic and pathogenic aspects (work ability and general health).

These results are similar to results within the field of occupational health psychology in which Schaufeli and Salanova (2007) have documented that publications on negative states, such as depression and anxiety, exceed publications on positive states, such as happiness and life satisfaction, by a ratio of $16: 1$. Thus, it seems obvious that pathogenic thinking still prevails within psychology and health promotion, and that promoting salutogenic thinking within the realm of occupational health is highly needed.

\section{Making Salutogenesis Visible}

Individual-level interventions most commonly strengthen psychosocial resources with regard to appraisal of and coping with job demands, which corresponds with Antonovsky's view of generalized resistance resources and sense of coherence as important factors in dealing with stressors and stressor-induced tension. In line with positive psychology in general (cf. Fredrickson, 2001; Seligman \& Csikszentmihalyi, 2000) and positive occupational health psychology (cf. Bakker \& Derks, 2010), individual-level interventions strengthen the awareness and competency of proactively building a resourceful environment and applying one's strengths and virtues to enhance positive well-being and health-see for example the self-tuning approach in this chapter (Vinje, 2007), the values in action (VIA) (Harzer \& Ruch, 2012; Peterson \& Seligman, 2004), job crafting (Tims \& Bakker, 2010; Wrzesniewski \& Dutton, 2001), psychological capital development (Luthans, Avey, Avolio, Norman, \& Combs, 2006), mindfulness training (Hülsheger, Alberts, Feinholdt, \& Lang, 2013), and positive psychology at work in general (Bono, Glomb, Shen, Kim, \& Koch, 2013; Mills, Fleck, \& Kozikowski, 2013).

Such approaches are ideally combined with participatory optimization processes, where teams, units, or entire companies engage in the collective endeavor of reducing job demands and enhancing job resources (Bauer \& Jenny, 2013). A core element of both individual and participatory optimization processes is analysis, i.e., a process of measuring, comparing, and-most elementary-of creating 
visibility of personal resources, job demands and resources, and health and well-being. Analysis is not only a technical precondition of optimization (Inauen, Jenny, \& Bauer, 2012), but the beginning of a narrative of work and health, within both the individual and the system. At this point of the intervention, the change agent triggers the story of salutogenesis, making salutogenesis visible and part of communication routines. Following, an example shows how a survey-feedback process can foster salutogenic thinking in organizations by putting a strong focus on job resources and positive outcomes.

\section{The ARK Intervention Programme: A Salutogenic Focus in Academic Institutions}

The work environment and climate survey for higher education institutions, called the ARK Intervention Programme (Undebakke, Innstrand, Anthun, \& Christensen, 2015), was initiated by the four largest universities in Norway and was developed in cooperation with the Centre for Health Promotion Research at the Norwegian University of Science and Technology. The aim of the project was to develop a work environment and climate survey specifically for employees in higher education institutions and to promote workplace health by use of survey-feedback processes. The universities and university colleges in the Nordic countries can use ARK to get necessary support and training (technical, pedagogi$\mathrm{cal}$, and practical) in conducting the survey and the feedback processes at their own cost.

The institutions taking part must commit to the following issues: (a) the survey-feedback processes should be well anchored in the top and local management levels and in the unions; (b) the institutions must commit to following up on the results and improving the working conditions agreed upon as a result of the survey and other processes at the workplaces; and (c) all of the quantitative data collected by the questionnaire used in the ARK Programme should be collected in the national research database, HUNT (Helseundersøkelsen i Nord-Trøndelag, 2014) and be available for researchers interested in work environment and health promotion in higher education institutions.

The survey-feedback processes were inspired by Bechard's (1969) recommendations on organizational development. They contain five phases: (1) preparation and anchoring (discussions between head of department and safety representatives, preparation and training, information to employees); (2) screening (electronic surveys, feedback of results to management and safety representatives as well as to all employees by trained personnel, group discussions regarding demands and resources, and possible job-condition improvements, with the head of department summarizing and explaining further processes);
(3) development of actions and follow-up (the head of department is responsible for involving employees in developing realistic, concrete, and important interventions); (4) implementation of actions (and follow-up by the management); and (5) evaluation (at every stage through the process). The five phases should be reconducted after 2-3 years.

The questionnaire used in the electronic survey in the screening phase was developed from other validated instruments and was adjusted according to the needs of higher education institutions (Undebakke et al., 2015). It was strongly inspired by the JD-R model (Bakker \& Demerouti, 2007) as all work environment measures are divided into job demands and resources and as it includes a particular focus on work engagement (Schaufeli \& Bakker, 2010) and also a work-related sense of coherence (Vogt et al., 2013). In feedback meetings, employees are briefed about differences between positive (salutogenic) and negative (pathogenic) health, and the JD-R model with its two different pathways is important for engagement and wellbeing and for burnout and disease. This presentation is given before the results of the survey are presented and is meant to encourage employees to discuss the importance of not only risk factors and prevention of disease but also job resources and positive outcomes, such as work engagement and productivity. Thus, the intention of the survey-feedback process is to encourage the employees and the heads of departments to take an active stance on whether they mainly want to prioritize a salutogenic process or a "pathogenic" riskprevention process.

The ARK Intervention Programme has received considerable interest since it was launched in the summer of 2013, and more than 15 educational institutions with several thousand employees have initiated processes using the approaches developed within it. Preliminary results of participatory observations indicate that the JD-R model is easy to understand and that it fosters fruitful discussions regarding salutogenic working conditions and health among employees in higher education institutions.

\section{Discussion}

This chapter has shown that promoting and sustaining salutogenic work will comprise practices at the individual, group, and organizational levels. On the individual level, practices like self-tuning are encouraged to aim at an active and profound involvement with oneself and one's work environment. Such practices focus on personal strengths, resources, values, and calling to one's profession, as well as the skills to experience and reflect upon them. Similarly, collective-level practices in groups or organizations point to the capacity for self-monitoring and self-optimization with a 
focus on (job) resources and positive outcomes, supported by corresponding indicators, tools, labels, and methods of change.

From a professional perspective-be it human resource managers, workplace health promoters, occupational health and safety specialists, or consultants, trainers, and coachesthese practices need to gain strategic weight to compete and prevail within corporate politics and routines. Salutogenesis practice faces the challenge of connecting to the logic of management without betraying the ideal and vision of selffulling individuals finding meaning, zest, and vitality at work. From this chapter, the implication can be drawn that the JD-R model has the potential to serve as such a connecting element. Furthermore, self-monitoring tools with an explicit focus on job resources and positive outcomes have been developed on this basis. The concept and scale of Work-SoC could be used to broadly introduce salutogenic thinking and acting to worksites. These individual and collective monitoring, tuning, and optimization practices could be blended into one coherent practice and then be aligned with organizational logic. As boundaries between working life and other life domains increasingly blur, such salutogenic intervention approaches will need to consider the interface between working life and private life in the future.

Research on salutogenic work strives to understand the underlying mechanism of (positive) health development at work. This chapter has reported examples of quantitative and qualitative studies exploring salutogenic pathways at work for both the individual and the collective, and it also reflected on the social context wherein the construction of meaning and value occurs. In general, the JD-R model has proven to be very helpful for corresponding theory development and generating new hypotheses to be tested, particularly regarding positive health development. Some measures have been presented, but it remains clear that the field lacks indicators and instruments for measuring positive health, which might be due to the lack of a concise definition of this phenomena to be measured (cf. Bringsén, Andersson, \& Ejlertsson, 2009; Keyes, 2007; Seligman, 2008). Here, researchers face the challenging task of developing a coherent concept of positive health in order to show how work affects it. Similarly, the concept of meaning (at work and in/of life), its relationship to positive health, and its role in health development need to be further detailed through interdisciplinary reviews and both quantitative and qualitative research (cf. Glazer et al., 2014).

The concept of Work-SoC also raises interesting research questions, for example, whether the causal and possibly reciprocal relationship of Work-SoC and general sense of coherence can be empirically demonstrated, and what roles job demands, job resources, and other personal resources play in this process. Intervention and evaluation research will parallel these developments to further prove causality and to strengthen the evidence-base and arguments for salutogenic practice, as described above. A compilation of current intervention approaches with a salutogenic orientation have been presented by Bauer and Jenny (2013). Finally, research on the work-nonwork interface provides a rich source of models explaining how health develops in relation to different life roles, including working life (cf. Allen, 2012; Geurts \& Demerouti, 2003). For now, this large body of research has not been linked with the concept of salutogenesis.

\section{Challenges for the Future}

Making work rich and decent-to recapitulate Lewin's words cited at the beginning of this chapter-seems more of an imperative than a choice. The challenge lies in aligning the involved systems with their competing objectives and possibly contradictory logics: the individual as a bio-psychosocial system with a self-preserving and self-enhancing drive, private companies as complex social systems with market-based and resource-oriented strategies, politics as a system of stakeholders and lobbyists with law-making powers, and society in general as an overarching construction transporting shared values and norms for individual and collective sense-making, identity-building, and guidance through a complex world. A salutogenic paradigm with regard to work will have to consider diffusion of innovation techniques on the macro, meso, and micro levels, which inevitably demands the formation of networks and lobbyists.

As an example, researchers involved in organizational health intervention research recently formed the International Network for Sustainable Organizational Interventions (INSOI) to coordinate appearances at conferences and share their findings from research in the field. Such networks might also foster transdisciplinary research, comprising members from the many areas of psychology, sociology, public health, and others (cf. Bauer \& Hämmig, 2014), which could lead to a comprehensive concept of salutogenic work. However, the act of defining and measuring salutogenic work means creating a "difference that makes difference" (Bateson, 1972), and it will take considerable effort to defend this difference-making against opposing forces that wish to leave positive health and selfdevelopment at work in the realm of unmarked phenomena, thus ensuring that it stays a non-binding and personal issue free from institutional or legislative requirements and consequences.

Finally, as noted in the self-tuning approach and remarked upon by Schallberger (2006), the interplay between the positive and negative paths of health development at work need to be researched, to ensure that positive 
health development does not cause unforeseen negative side effects, for example, in the form of biased appraisals and prolonged endurance of excessive overload due to strong experiences of meaning at work.

Open Access This chapter is distributed under the terms of the Creative Commons Attribution-Noncommercial 2.5 License (http:// creativecommons.org/licenses/by-nc/2.5/) which permits any noncommercial use, distribution, and reproduction in any medium, provided the original author(s) and source are credited.

The images or other third party material in this chapter are included in the work's Creative Commons license, unless indicated otherwise in the credit line; if such material is not included in the work's Creative Commons license and the respective action is not permitted by statutory regulation, users will need to obtain permission from the license holder to duplicate, adapt or reproduce the material.

\section{References}

Adkins, J. A. (1999). Promoting organizational health: The evolving practice of occupational health psychology. Professional Psychology: Research and Practice, 30(2), 129-137. doi:10.1037/07357028.30.2.129.

Albertsen, K., Nielsen, M. L., \& Borg, V. (2001). The Danish psychosocial work environment and symptoms of stress: The main, mediating and moderating role of sense of coherence. Work \& Stress, 15(3), 241-253. doi:10.1080/02678370110066562.

Allen, T. D. (2012). The work-family role interface: A synthesis of the research from industrial and organizational psychology. In I. B. Weiner, N. W. Schmitt, \& S. Highhouse (Eds.), Handbook of psychology, Vol. 12, Industrial and organizational psychology (2nd ed., pp. 698-718). Hoboken, NJ: Wiley. doi:10.1002/ 9781118133880.hop212026.

Antonovsky, A. (1987a). Health promoting factors at work: the sense of coherence. In C. L. Cooper, R. Kalimo, \& M. El-Batawi (Eds.), Psychosocial factors at work and their relation to health (pp. 153-167). Geneva: WHO.

Antonovsky, A. (1987b). Unraveling the mystery of health: How people manage stress and stay well. San Francisco, CA: Jossey-Bass.

Bakibinga, P., Vinje, H. F., \& Mittelmark, M. B. (2012). Self-tuning for job engagement: Ugandan nurses' self-care strategies in coping with work stress. International Journal of Mental Health Promotion, 14(1), 3-12. doi:10.1080/14623730.2012.682754.

Bakker, A. B., \& Demerouti, E. (2007). The job demands-resources model: State of the art. Journal of Managerial Psychology, 22(3), 309-328. doi:10.1108/02683940710733115.

Bakker, A. B., Demerouti, E., \& Euwema, M. C. (2005). Job resources buffer the impact of job demands on burnout. Journal of Occupational Health Psychology, 10(2), 170-180. doi:10.1037/1076-8998. 10.2.170.

Bakker, A. B., \& Derks, D. (2010). Positive occupational health psychology. In S. Leka \& J. Houdmont (Eds.), Occupational health psychology (pp. 194-224). Oxford: Wiley-Blackwell.

Bakker, A. B., Hakanen, J. J., Demerouti, E., \& Xanthopoulou, D. (2007). Job resources boost work engagement, particularly when job demands are high. Journal of Educational Psychology, 99(2), 274-284. doi:10.1037/0022-0663.99.2.274.

Bateson, G. (1972). Steps to an ecology of mind: Collected essays in anthropology, psychiatry, evolution, and epistemology. London: Intertext Books.
Bauer, G. F., Davies, J. K., \& Pelikan, J. (2006). The EUHPID Health Development Model for the classification of public health indicators. Health Promotion International, 21, 153-159.

Bauer, G. F., \& Hämmig, O. (2014). Bridging occupational, organizational and public health. Dordrecht, The Netherlands: Springer.

Bauer, G. F., \& Jenny, G. J. (2007). Development, implementation and dissemination of occupational health management (OHM): Putting salutogenesis into practice. In J. Houdmont, \& S. McIntyre (Eds.), Occupational health psychology: European perspectives on research, education and practice (pp. 219-250). Castelo da Maia: ISMAI.

Bauer, G. F., \& Jenny, G. J. (2012). Moving towards positive organizational health: Challenges and a proposal for a research model of organizational health. In J. Houdmont, S. Leka, \& R. R. Sinclair (Eds.), Contemporary occupational health psychology: Global perspectives on research and practice (pp. 126-145). Chichester: Wiley.

Bauer, G. F., \& Jenny, G. J. (Eds.). (2013). Salutogenic organizations and change: The concepts behind organizational health intervention research. Dordrecht: Springer.

Bauer, G. F., Vogt, K., Inauen, A., \& Jenny, G. J. (2015). Work-SoCEntwicklung und Validierung einer Skala zur Erfassung des arbeitsbezogenen Kohärenzgefühls. Zeitschrift Für Gesundheitspsychologie, 23(1), 20-30. doi:10.1026/0943-8149/a000132.

Bechard, R. (1969). Organization development. Its nature, origin and prospects. Reading, MA: Addison-Wesley.

Bono, J. E., Glomb, T. M., Shen, W., Kim, E., \& Koch, A. J. (2013). Building positive resources: Effects of positive events and positive reflection on work stress and health. Academy of Management Journal, 56(6), 1601-1627. doi:10.5465/amj.2011.0272.

Brauchli, R., Jenny, G. J., Füllemann, D., \& Bauer, G. F. (2015). Towards a job demands-resources health model: Empirical testing with generalizable indicators of job demands, job resources, and comprehensive health outcomes. BioMed Research International http://dx.doi.org/10.1155/2015/959621

Brauchli, R., Schaufeli, W. B., Jenny, G. J., Füllemann, D., \& Bauer, G. F. (2013). Disentangling stability and change in job resources, job demands, and employee well-being-A three-wave study on the Job-Demands Resources model. Journal of Vocational Behavior, 83 (2), 117-129.

Bringsén, Å., Andersson, H. I., Ejlertsson, G., \& Troein, M. (2012). Exploring workplace related health resources from a salutogenic perspective: Results from a focus group study among healthcare workers in Sweden. Work, 42(3), 403-414. doi:10.3233/WOR2012-1356.

Bringsén, Å., Andersson, H. I., \& Ejlertsson, G. (2009). Development and quality analysis of the Salutogenic Health Indicator Scale (SHIS). Scandinavian Journal of Public Health, 37(1), 13-19. doi:10.1177/1403494808098919.

Deci, E. L., \& Ryan, R. M. (1985). Intrinsic motivation and selfdetermination in human behavior. New York: Plenum Press.

ENWHP. (2005). The Luxembourg declaration on workplace health promotion in the European union. Luxembourg: European Network for Workplace Health Promotion. Retrieved from http://www. enwhp.org/fileadmin/downloads/free/Luxembourg_Declaration_ June2005_final.pdf

Eriksson, M., \& Lindström, B. (2005). Validity of Antonovsky's sense of coherence scale: a systematic review. Journal of Epidemiology and Community Health, 59(6), 460-466. doi:10.1136/jech.2003. 018085.

Feldt, T. (1997). The role of sense of coherence in well-being at work: Analysis of main and moderator effects. Work \& Stress, 11(2), 134-147. doi:10.1080/02678379708256830. 
Feldt, T., Kinnunen, U., \& Mauno, S. (2000). A mediational model of sense of coherence in the work context: A one-year follow-up study. Journal of Organizational Behavior, 21(4), 461-476. doi:10.1002/( SICI)1099-1379(200006)21:4<461::AID-JOB11>3.0.CO;2-T.

Fredrickson, B. L. (2001). The role of positive emotions in positive psychology. American Psychologist, 56(3), 218-226. doi:10.1037/ 0003-066X.56.3.218.

Geurts, S. A. E., \& Demerouti, E. (2003). Work/non-work interface: A review of theories and findings. In M. J. Schabracq, J. A. M. Winnubst, \& C. L. Cooper (Eds.), The handbook of work and health psychology (2nd ed., pp. 279-312). New York: Wiley.

Glazer, S., Kozusznik, M. W., Meyers, J. H., \& Ganai, O. (2014). Cultural implications of meaningfulness as a resource to mitigate work stress. In S. Leka \& R. Sinclair (Eds.), Contemporary occupational health psychology: Global perspectives on research and practice (pp. 114-130). Hoboken: Wiley.

Hakanen, J. J., Bakker, A. B., \& Schaufeli, W. B. (2006). Burnout and work engagement among teachers. Journal of School Psychology, 43(6), 495-513.

Hakanen, J. J., Perhoniemi, R., \& Toppinen-Tanner, S. (2008). Positive gain spirals at work: From job resources to work engagement, personal initiative and work-unit innovativeness. Journal of Vocational Behavior, 73(1), 78-91. doi:10.1016/j.jvb.2008.01.003.

Hakanen, J. J., \& Schaufeli, W. B. (2012). Do burnout and work engagement predict depressive symptoms and life satisfaction? A three-wave seven-year prospective study. Journal of Affective Disorders, 141(2-3), 415-424. doi:10.1016/j.jad.2012.02.043.

Hallberg, U. E., \& Schaufeli, W. B. (2006). "Same" but different: Can work engagement be discriminated from job involvement and organizational commitment? European Psychologists, 11(2), 119-127. doi:10.1027/1016-9040.11.2.119.

Hanson, A. (2007). Workplace health promotion. A salutogenic approach. Bloomington: AuthorHouse.

Harzer, C., \& Ruch, W. (2012). When the job is a calling: The role of applying one's signature strengths at work. The Journal of Positive Psychology, 7(5), 362-371. doi:10.1080/17439760.2012.702784.

Helseundersøkelsen i Nord-Trøndelag. (2014). Retrieved April 14, 2015, from http://www.ntnu.no/hunt

Hoffmann, S., Jenny, G. J., \& Bauer, G. F. (2014). Capacity building as a key mechanism of organizational health development. In G. F. Bauer \& O. Hämmig (Eds.), Bridging occupational, organizational and public health (pp. 103-116). Dordrecht: Springer.

Hülsheger, U. R., Alberts, H. J. E. M., Feinholdt, A., \& Lang, J. W. B. (2013). Benefits of mindfulness at work: the role of mindfulness in emotion regulation, emotional exhaustion, and job satisfaction. The Journal of Applied Psychology, 98(2), 310-325. doi:10.1037/ a0031313.

Idan, O., Braun-Lewensohn, O., \& Sagy, S. (2013). Qualitative, sense of coherence-based assessment of working conditions in a psychiatric in-patient unit to guide salutogenic interventions. In G. F. Bauer \& G. J. Jenny (Eds.), Salutogenic organizations and change: The concepts behind organizational health intervention research (pp. 55-74). Dordrecht: Springer.

ILO. (2014). Jobs and livelihoods at the heart of the post-2015 development agenda. Retrieved March 12, 2014, from http://www.ilo. org/global/topics/post-2015/documents/WCMS_193483/lang--en/ index.htm

Inauen, A., Jenny, G. J., \& Bauer, G. F. (2012). Design principles for data- and change-oriented organisational analysis in workplace health promotion. Health Promotion International, 27(2), 275-283. doi:10.1093/heapro/dar030.

Jenny, G. J., \& Bauer, G. F. (2013). The limits of control: A systemic, model-based approach to changing organisations towards better health. In G. F. Bauer \& G. J. Jenny (Eds.), Salutogenic organizations and change: The concepts behind organizational health intervention research (pp. 167-187). Dordrecht: Springer. doi:10.1007/978-94-007-6470-5_10.

Karasek, R. A., \& Theorell, T. (1990). Healthy work: Stress, productivity, and the reconstruction of working life. New York: Basic Books.

Keyes, C. L. M. (2007). Promoting and protecting mental health as flourishing: A complementary strategy for improving national mental health. The American Psychologist, 62(2), 95-108. doi:10.1037/ 0003-066X.62.2.95.

Lewin, K. (1920). Die Sozialisierung des Taylorsystems. Eine grundsätzliche Untersuchung zur Arbeits- und Berufspsychologie. Berlin: Verlag für Gesellschaft und Erziehung.

Luthans, F., Avey, J., Avolio, B. J., Norman, S. M., \& Combs, G. M. (2006). Psychological capital development: Toward a microintervention. Journal of Organizational Behavior, 27(3), 387-393.

Mayer, C.-H., \& Krause, C. (2011). Promoting mental health and salutogenesis in transcultural organizational and work contexts. International Review of Psychiatry, 23(6), 495-500. doi:10.3109/ 09540261.2011.636549.

Mills, M. J., Fleck, C. R., \& Kozikowski, A. (2013). Positive psychology at work: A conceptual review, state-of-practice assessment, and a look ahead. The Journal of Positive Psychology, 8(2), 153-164. doi:10.1080/17439760.2013.776622.

Mittelmark, M. B., \& Bull, T. (2013). The salutogenic model of health in health promotion research. Global Health Promotion, 20(2), 30-38. doi:10.1177/1757975913486684.

Nilsson, P., Andersson, I. H., Ejlertsson, G., \& Troein, M. (2012). Workplace health resources based on sense of coherence theory. International Journal of Workplace Health Management, 5(3), 156-167. doi:10.1108/17538351211268809.

Nortvedt, P., \& Grimen, H. (2004). Sensibilitet og Refleksjon. Filosofi og vitenskapsteori for helsefag. Oslo: yldendal Norsk Forlag AS.

Peterson, U., Demerouti, E., Bergström, G., Samuelsson, M., Åsberg, M., \& Nygren, A. (2008). Burnout and physical and mental health among Swedish healthcare workers. Journal of Advanced Nursing, 62(1), 84-95. doi:10.1111/j.1365-2648.2007.04580.x.

Peterson, C., \& Seligman, M. E. P. (2004). Character strengths and virtues: A handbook and classification. Washington, DC: APA Press.

Saks, A. (2006). Antecedents and consequences of employee engagement. Journal of Managerial Psychology, 21(7), 600-619. doi:10. 1108/02683940610690169.

Salanova, M., Llorens, S., \& Schaufeli, W. B. (2011). "Yes, I Can, I Feel Good, and I Just Do It!" On gain cycles and spirals of efficacy beliefs, affect, and engagement. Applied Psychology, 60(2), 255-285. doi:10.1111/j.1464-0597.2010.00435.x.

Schallberger, U. (2006). Die zwei Gesichter der Arbeit und ihre Rolle für das Wohlbefinden: Eine aktivierungstheoretische Interpretation [The two faces of work and their roles in well-being: an interpretation based on activation theory]. Wirtschaftspsychologie: Sonderheft Zur Salutogenese in Der Arbeit, 2(3), 97-103.

Schaufeli, W. B., \& Bakker, A. B. (2010). Defining and measuring work engagement: Bringing clarity to the concept. In A. B. Bakker \& M. P. Leiter (Eds.), Work engagement. A handbook of essential theory and research (pp. 10-24). London: Duke University Press.

Schaufeli, W. B., \& Salanova, M. (2007). Work engagement: An emerging psychological concept and its implications for organizations. In S. W. Gilliland, D. D. Steiner, \& D. P. Skarlicki (Eds.), Managing social and ethical issues in organizations (pp. 135-177). Greenwich: Information Age.

Schaufeli, W. B., \& Taris, T. W. (2014). A critical review of the Job Demands-Resources Model: Implications for improving work and health. In G. F. Bauer \& O. Hämmig (Eds.), Bridging occupational, organizational and public health (pp. 43-68). Dordrecht: Springer. 
Seligman, M. E. P. (2008). Positive health. Applied Psychology, 57 (Suppl. 1), 3-18. doi:10.1111/j.1464-0597.2008.00351.x.

Seligman, M. E. P., \& Csikszentmihalyi, M. (2000). Positive psychology-An introduction. American Psychologist, 55(1), 5-14. doi:10. 1037//0003-066x.55.1.5.

Stewart, A. L., Hays, R. D., \& Ware, J. E. (1992). Methods of constructing health measures. In A. L. Stewart \& J. E. Ware (Eds.), Measuring functioning and well-being (pp. 67-85). London: Duke University Press.

Tims, M., \& Bakker, A. B. (2010). Job crafting: Towards a new model of individual job redesign. SA Journal of Industrial Psychology, 36 (2), 1-9. doi:10.4102/sajip.v36i2.841.

Togari, T., Yamazaki, Y., Nakayama, K., \& Shimizu, J. (2007). Development of a short version of the sense of coherence scale for population survey. Journal of Epidemiology and Community Health, 61(10), 921-922. doi:10.1136/jech.2006.056697.

Torp, S., Grimsmo, A., Hagen, S., Duran, A., \& Gudbergsson, S. B. (2013). Work engagement: A practical measure for workplace health promotion. Health Promotion International, 28(3), 387-396. doi:10.1093/heapro/das022.

Torp, S., \& Vinje, H. F. (2014). Is workplace health promotion research in the Nordic countries really on the right track? Scandinavian Journal of Public Health, 42(15 Suppl), 74-81. doi:10.1177/ 1403494814545106.

Udris, I. (2006). Salutogenese in der Arbeit: ein Paradigmenwechsel? [Salutogenesis at work: A change in paradigms?]. Wirtschaftspsychologie, Sonderheft Zur Salutogenese in Der Arbeit, 8(2/3), 4-13.

Undebakke, K., Innstrand, S. T., Anthun, K. S., \& Christensen, M. (2015). The ARK intervention Programme: Who-What-How. Trondheim. Retrieved from http://www.ntnu.no/documents/34221120/0/2015 01_ARK_web.pdf/65dd9de7-b61f-4f0b-9829-bf87dd58cfda

Vaandrager, L., \& Koelen, M. (2013). Salutogenesis in the workplace: Building general resistance resources and sense of coherence. In G. F. Bauer \& G. J. Jenny (Eds.), Salutogenic organizations and change: The concepts behind organizational health intervention research (pp. 77-89). Dordrecht: Springer.

Van den Broeck, A., Van Ruysseveldt, J., Vanbelle, E., \& de Witte, H. (2013). The job demands-Resources model: Overview and suggestions for future. Advances in Positive Organizational Psychology, 1, 83-105. doi:10.1108/S2046-410X(2013)0000001007.
Van der Doef, M., \& Maes, S. (1999). The Job Demand-Control (-Support) Model and psychological well-being: A review of 20 years of empirical research. Work \& Stress, 13(2), 87-114. doi:10.1080/026783799296084.

Vinje, H. F. (2007). Thriving despite adversity: Job engagement and self-care among community nurses. Dissertation. University of Bergen.

Vinje, H. F., \& Ausland, L. H. (2013). Salutogenic presence supports a health-promoting work life. Socialmedicinsk Tidskrif T, 6, 890-901.

Vinje, H. F., \& Mittelmark, M. B. (2006). Deflecting the path to burnout among community health nurses: How the effective practice of self-tuning renews job engagement. International Journal of Mental Health Promotion, 8(4), 36-47.

Vinje, H. F., \& Mittelmark, M. B. (2007). Job engagement's paradoxical role in nurse burnout. Nursing and Health Sciences, 9(2), 107-111. doi:10.1111/j.1442-2018.2007.00310.x.

Vinje, H. F., \& Mittelmark, M. B. (2008). Community nurses who thrive: The critical role of job engagement in the face of adversity. Journal for Nurses in Staff Development, 24(5), 195-202. doi:10. 1097/01.NND.0000320695.16511.08.

Vogt, K., Jenny, G. J., \& Bauer, G. F. (2013). Comprehensibility, manageability and meaningfulness at work: Construct validity of a scale measuring work-related sense of coherence. SA Journal of Industrial Psychology, 39(1), 1-8. doi:10.4102/sajip.v39i1.1111.

WHO. (2006). Declaration on workers health. Geneva: WHO. Retrieved from http://www.who.int/occupational_health/Declarwh.pdf

WHO. (2007). Workers' health: Global plan of action. Geneva: WHO. Retrieved from http://www.who.int/entity/occupational_health/ WHO_health_assembly_en_web.pdf

WHO. (2010). WHO healthy workplace framework and model: Background and supporting literature and practice. Geneva: WHO. Retrieved from http://www.who.int/occupational_health/healthy_ workplace_framework.pdf

WHO. (2013). WHO global plan of action on workers' health (2008-2017): Baseline for implementation. Geneva: WHO. Retrieved from http://www.who.int/occupational_health/who_ workers_health_web.pdf

Wrzesniewski, A., \& Dutton, J. E. (2001). Crafting a job: As active employees revisioning crafters of their work. The Academy of Management Review, 26(2), 179-201. doi:10.2307/259118. 